\title{
Modification of softwood kraft pulp fibres using hydrogen peroxide at acidic conditions
}

\author{
Axel Martinsson (D) Merima Hasani $(\mathbb{D})$ Antje Potthast $(\mathbb{D} \cdot$ Hans Theliander $(\mathbb{C})$
}

Received: 27 January 2020/ Accepted: 18 May 2020/Published online: 27 May 2020

(C) The Author(s) 2020

\begin{abstract}
The aim of this work was to provide softwood kraft pulp fibres with new functionalities by the introduction of carbonyl groups. Carbonyl groups are known to affect properties such as wet strength through the formation of covalent bonds, i.e. hemiacetals. The method developed involves oxidation using hydrogen peroxide at mildly acidic conditions. It was found that the carbonyl group content increased with both increasing temperature and residence time when oxidized at acidic conditions. The number of carboxylic groups, however, remained approximately constant. There was virtually no increase in carbonyl groups when oxidation was performed at alkaline conditions. The maximum increase in carbonyl groups was found at a residence time of $90 \mathrm{~min}$, a reaction temperature of $85^{\circ} \mathrm{C}$ and a $\mathrm{pH}$ of 4 . These conditions resulted in an increase in carbonyl groups from 30 to
\end{abstract}

A. Martinsson · M. Hasani $(\bowtie) \cdot H$. Theliander Department of Chemistry and Chemical Engineering, Chalmers University of Technology, 41296 Gothenburg, Sweden

e-mail: merima.hasani@chalmers.se

M. Hasani $\cdot$ H. Theliander

Wallenberg Wood Science Center, The Royal Institute of Technology, Chalmers University of Technology, 10044 Stockholm, Sweden

\section{A. Potthast}

Division of Chemistry of Renewables, Department of Chemistry, University of Natural Resources and Life

Sciences Vienna, Muthgasse 18, 1190 Vienna, Austria
$122 \mu \mathrm{mol} / \mathrm{g}$. When formed into a sheet, the pulp oxidized at acidic conditions proved to maintain its structural integrity at aqueous conditions. This indicates the formation of hemiacetal bonds between the introduced carbonyl groups and the hydroxyl groups on the carbohydrate chains. Thus, a possible application for the method could be fibre modification during the final bleaching stage of softwood kraft pulp, where the wet strength of the pulp could be increased.

Keywords Hydrogen peroxide - Cellulose oxidation · Carbonyl groups · Wet strength $\cdot$ Bleaching

\section{Introduction}

Wet strength is an important property in some paperbased products, e.g. various packaging and absorbing applications. It is not easily achieved, however, because when a paper material is wetted, the interfibre hydrogen bonds that keep the material together are broken; the strength of the material is reduced by more than 90\% (Dunlop-Jones 1991). Although techniques such as wet pressing and refining have been implemented to overcome this and reduce the loss in strength, they nevertheless have a very limited effect on the wet strength. Wet strength agents are therefore commonly added to increase the wet strength further, after which between 10 and $30 \%$ of the initial strength 
can be maintained under wet conditions. These additives can be expensive and have negative environmental impacts or health hazards, both in use and in production. Aldehyde-based additives, such as urea formaldehyde and melamine formaldehyde, require formaldehyde in their manufacture, which is a known carcinogen. The production of polyamide or epoxidebased additives are associated with emissions of adsorbable organic halides (AOX). These additives can also cause issues when the fibre material is repulped, as they result in apermanent increase in wetstrength, which requires oxidizing treatments to successfully re-pulp (Bates et al. 1999; Epsy and Geist 1993). Another wet strength agent also used is dialdehyde starch which, unfortunately, is linked to effluent emissions of iodine as a result of the sodium periodate used for oxidation (Bates et al. 1999). The action of these aldehyde-based additives relies on the introduction of covalent bonds, i.e. hemiacetals, between the aldehyde groups of the additives and the hydroxyl groups in the carbohydrate structure. These covalent bonds are not broken by water as rapidly as the hydrogen bonds that normally hold the fibre network together. The addition of the above-mentioned wet strength agents could be avoided altogether if aldehyde groups could be introduced to the cellulose structure itself by appropriate oxidation.

Oxidizers such as chlorine dioxide, ozone and hydrogen peroxide are commonly used in the pulp bleaching process; the conditions are optimized to favour the removal of residual lignin while minimizing reactions with cellulose. If the conditions of the final bleaching stage could be altered to favour the formation of carbonyl groups on the fibre surface, the resulting pulp could have sufficient wet strength due to

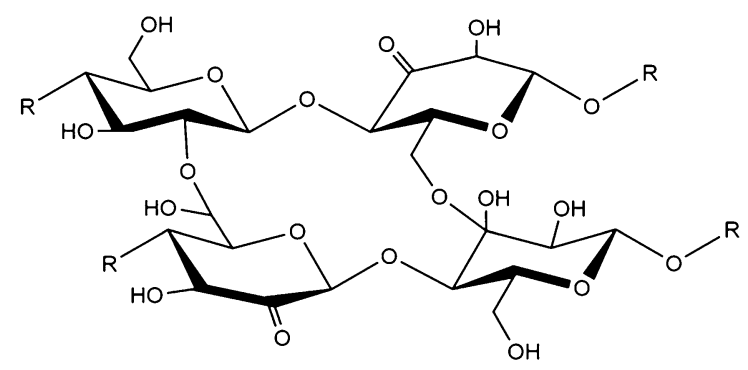

Fig. 1 Cellulose chains cross-linked by the formation of hemiacetals or hemiketals between neighbouring carbonyl and hydroxyl groups. Here, a C6 hemiacetal and a C3 hemiketal are shown the cross-linking effect of the carbonyls and thus not require any additives (Fig. 1). Of the more common bleaching agents available, hydrogen peroxide is a good candidate; being chlorine free, it is suitable for both ECF and TCF applications. It is also commonly used as a final stage in the production of high brightness pulps and is moreover an economical alternative to ozone.

When oxidizing cellulose using hydrogen peroxide, the hydroxyl radicals formed are capable of oxidizing the secondary alcohols at the $\mathrm{C} 2$ and $\mathrm{C} 3$ positions, as well as the primary alcohol at C6 to form carbonyl groups. This reaction is initiated by the abstraction of hydrogen from the respective carbon by the hydroxyl radical, followed by the elimination of a superoxide anion radical (Lewin 1997; Gierer 1997). One process parameter that could be altered to favour carbonyl formation when bleaching with hydrogen peroxide is the $\mathrm{pH}$. Hydrogen peroxide bleaching is usually performed under alkaline conditions, with a final $\mathrm{pH}$ of around 10.5-11 (Gullichsen and Fogelholm 1999). The fact that oxidation using acidic conditions favours the formation of carbonyl groups, and alkaline oxidation favours the formation of carboxylic groups, has been long known (Rutherford and Harris 1943). Changing the $\mathrm{pH}$ in a hydrogen peroxide bleaching stage could potentially yield a pulp with drastically altered properties.

The aim of this study was to investigate hydrogen peroxide oxidation as a tool for modifying softwood kraft fibres. The effects of process parameters such as $\mathrm{pH}$ and temperature on the formation of oxidized functionalities on the fibres, as well as the degradation of the carbohydrates, are evaluated. Furthermore, the fibre network integrity of the oxidised pulp in water is evaluated and compared to a fully-bleached kraft pulp.

\section{Experimental section}

Materials

A fully-bleached, softwood kraft pulp was provided by Södra Cell Värö. Hydrogen peroxide, hydroxylamine hydrochloride, sodium hydroxide, bis (ethylenediamine) copper (II) hydroxide solution, peracetic acid (40\%), sulphuric acid, hydrochloric acid, sodium chloride and sodium borohydride were purchased 
from Sigma-Aldrich. All reagents were of analytical quality and used as received.

\section{Oxidation of bleached kraft pulp}

The fully-bleached kraft pulp was oxidized using hydrogen peroxide. The reaction was performed in a jacketed glass reactor equipped with baffles. The vessel was heated using a circulating heater and stirred using a pitched blade impeller rotating at $1000 \mathrm{rpm}$. The oxidation was performed at a pulp consistency of $2.5 \%$ and a hydrogen peroxide concentration of $5 \%$ (of total weight of the liquid fraction). The starting $\mathrm{pH}$ of the reaction was adjusted to 4 for the acidic experiments and 10 for the alkaline oxidations, using either sulphuric acid or sodium hydroxide. No adjustment of the $\mathrm{pH}$ was made for the experiments performed in buffered solutions.

After oxidation, the reaction was quenched by adding $500 \mathrm{ml}$ of cold deionized water. The suspension was filtered and the filtrate recirculated once, followed by washing using $1000 \mathrm{ml}$ of deionized water. The filter cake was then allowed to rest in $500 \mathrm{ml}$ of deionized water for $10 \mathrm{~min}$, filtered off and the filtrate recirculated once again. Finally, the filter cake was washed using $1000 \mathrm{ml}$ of deionized water, $\mathrm{pH}$ adjusted to $\mathrm{pH} 3.5$ using sulphuric acid to minimize the impact of degradation due to $\beta$-alkoxyelimination (Münster et al. 2017; Hosoya et al. 2018). One portion of the washed pulp was then solvent exchanged with $95 \% \mathrm{EtOH}$. The samples were stored refrigerated.

The various experiments had residence times that varied between 30 and $90 \mathrm{~min}$ and temperatures that varied between 50 and $85{ }^{\circ} \mathrm{C}$. As the suspension was not expected to have any oxidizing effect without the presence of the hydrogen peroxide, no blank runs were performed.

Determination of carbonyl content using hydroxylamine hydrochloride

Carbonyl groups were quantified using a method based on that of Zhao and Heindel (1990). A $500 \mathrm{mg}$ sample (O.D. weight) of never-dried pulp was added to $50 \mathrm{ml}$ of deionized water, adjusted to $\mathrm{pH} 4$ using hydrochloric acid. Each sample was then stirred to disperse the fibres and, after $10 \mathrm{~min}$, filtered and washed using $50 \mathrm{ml}$ deionized water adjusted to $\mathrm{pH}$ 4. The sample was then added to $25 \mathrm{ml}$ of $0.25 \mathrm{M}$ hydroxylamine hydrochloride solution adjusted to $\mathrm{pH} 4$ and left for $2 \mathrm{~h}$ (at room temperature and constant mixing). The sample was thereafter filtered, and the filtrate titrated back to $\mathrm{pH} 4$ using $0.01 \mathrm{M} \mathrm{NaOH}$ (aq). The filter cake was placed in an oven at $105{ }^{\circ} \mathrm{C}$ for $24 \mathrm{~h}$ and used to determine the mass of the sample. The number of carbonyl groups were calculated using the amount of $\mathrm{NaOH}$ (aq) consumed in the titration and the dried weight of the sample. Analyses were performed in duplicates.

Determination of carboxyl content

by potentiometric titration

The carboxyl content of the pulp was analysed using a potentiometric titration method based on that of Barbosa et al. (2013). $0.5 \mathrm{~g}$ of (O.D. weight) neverdried pulp was placed in a flask containing $60 \mathrm{~mL}$ of $0.1 \mathrm{M}$ hydrochloric acid. The flask was then shaken to disperse the sample well and left at room temperature for $2 \mathrm{~h}$ to fully protonate the carboxyl groups. The sample was then washed with deionized water until the filtrate was neutral before being transferred to a $100 \mathrm{ml}$ beaker, where $50 \mathrm{~mL}$ of $0.5 \mathrm{M} \mathrm{NaCl}$ was added to control the ionic strength. The mixture was stirred continuously and titrated with $0.02 \mathrm{M} \mathrm{NaOH}$ (aq) in $0.5 \mathrm{M} \mathrm{NaCl}$ (aq). The number of carboxylic groups was thereafter calculated from the titrant volume at the equivalence point. After titration the sample was filtered and washed once again, and the filter cake used to determine the exact mass of the sample. Analyses were performed in duplicates.

\section{Intrinsic viscosity measurements}

The intrinsic viscosity of a sample dissolved in bis (ethylenediamine) copper (II) hydroxide solution was determined using capillary viscosimetry according to the SCAN-C 15:99 method. Intrinsic viscosity values were converted to viscosity-average molecular weight using the Mark-Houwink-Sakurada equation, employing the parameters calculated by Kes and Christensen (2013). Prior to making the viscosity measurements, the samples were reduced using $5 \%$ sodium borohydride at $4 \%$ consistency and room temperature for $24 \mathrm{~h}$ in order to prevent degradation due to $\beta$-alkoxyelimination. 
Determination of carbonyl content by CCOAlabelling

Carbazole-9-carbonyl-oxy-amine (CCOA) labelling of carbonyl groups was performed as described earlier by Röhrling et al. (2002). After labelling the samples, dissolution in N,N-dimethylacetamide/lithium chloride $9 \%(\mathrm{w} / \mathrm{v})(\mathrm{DMAc} / \mathrm{LiCl})$ was achieved after a solvent exchange at room temperature. Cellulose analysis was performed with a GPC (gel permeation chromatography) coupled with a MALLS (multi-angle laser light scattering)—fluorescence RI detection system, which yields the molecular weight distribution (MWD) in addition to the profiles of oxidised groups relative to the MWD.

The GPC system was comprised of a TSP FL2000 fluorescence detector for monitoring the label, a MALLS detector, (Wyatt Dawn DSP, Wyatt Inc., Santa Barbara, USA) with a diode laser $(\lambda=488 \mathrm{~nm})$ and a refractive index detector (Shodex RI-71). Four serial GPC columns, PL gel-mixed ALS, $20 \mu \mathrm{m}$ and $7.5 \times 300 \mathrm{~mm}$ (Agilent, Waldbronn, Germany) were used as the stationary phase. A degasser (Dionex DG2410), autosampler (HP 1100), pulse damper pump (Kontron pump 420) and column oven (Gynkotek STH 585) were also part of the system.

The operating conditions of the GPC were as follows: $1.00 \mathrm{~mL} / \mathrm{min}$ flow rate, $100 \mu \mathrm{L}$ injection volume, $45 \mathrm{~min}$ run time, $\lambda \mathrm{ex}=290 \mathrm{~nm}$ and $\lambda \mathrm{em}=$ $340 \mathrm{~nm}$ for fluorescence detection of the CCOA label. DMAc/LiCl $(0.9 \%, \mathrm{w} / \mathrm{v})$ was used as an eluent after filtering through a $0.02 \mu \mathrm{m}$ filter.

The data was evaluated using standard Chromeleon, Astra 4.73, and GRAMS/32 software.

\section{Compositional analysis}

The composition of the sample was determined using the method of Jedvert et al. (2012) which, in turn, is based on the research of Theander and Westerlund (1986). $3 \mathrm{ml}$ of $72 \% \mathrm{H}_{2} \mathrm{SO}_{4}$ (aq) was added to a sample of $200 \mathrm{mg}$ (O.D.), followed by evacuation for $15 \mathrm{~min}$. The sample was then placed in a $30{ }^{\circ} \mathrm{C}$ water bath for $1 \mathrm{~h}$ and stirred every twenty minutes; thereafter $84 \mathrm{~g}$ of deionized water was added before it was placed in an autoclave at $125^{\circ} \mathrm{C}$ for $1 \mathrm{~h}$. The sample was filtered and diluted 10 and 50 times respectively, with an addition of $8 \mathrm{mg} / \mathrm{l}$ fucose as an internal standard. The filter cake was dried and used for quantification of Klason lignin and the filtrate analysed for acid soluble lignin (ASL) using an Analytik Jena UV spectrometer at a wavelength of $205 \mathrm{~nm}$, with an absorptivity constant of $110 \mathrm{dm} 3 /$ $\mathrm{g} \mathrm{cm}$. The monomeric sugars were then analysed using a Dionex ICS-5000 equipped with CarboPac PA1 columns using $\mathrm{NaOH} / \mathrm{NaAc}(\mathrm{aq})$ and $\mathrm{NaOH}$ (aq) as eluents. Detection was performed using an electrochemical detector, using Chromeleon 7, Version 7.1.3.2425 as the software. For conversion of monomeric sugars to carbohydrates the molar ratio between mannose and glucose in galactoglucomannan was assumed to be 3.5:1 (Meier 1958).

Wet durability test

The impact that the oxidations had on the wet strength was evaluated by producing sheets from two different pulps: one reference pulp (bleached kraft pulp) and one highly oxidized pulp (carbonyl content: $121.6 \mu \mathrm{mol} / \mathrm{g}$ ). Each pulp was placed in a pulp disintegrator at 30,000 revs in $2 \mathrm{~L}$ of water. The slurry was then filtered using a Büchner funnel to produce the final sheet, which was then allowed to air dry. Once dry, a square of $3 \times 3 \mathrm{~cm}$ was cut out, placed in a beaker containing $400 \mathrm{~mL}$ of deionized water and observed over the following $2 \mathrm{~h}$ to monitor any changes. A stir bar was added after $48 \mathrm{~h}$, and the two samples were stirred for $1 \mathrm{~min}$ each at $120 \mathrm{rpm}$.

Analysis of total organic carbon

Analysis of total organic carbon (TOC) was performed according to the SS-EN 1484 standard. Total carbon (TC) is quantified by combusting the sample catalytically at $680^{\circ}$ and any $\mathrm{CO}_{2}$ produced is detected using an NDIR detector. Inorganic carbon (IC) is quantified as $\mathrm{CO}_{2}$ released during acidification with phosphoric acid. The TOC is calculated as the difference between the TC and IC.

Fibre image analysis

The dimensions of the fibres were analysed using a Kajaani FS300 fibre image analyser. A sample of $50 \mathrm{mg}$ of never-dried pulp was added to $2 \mathrm{~L}$ of deionized water and defibrillated for 30,000 revs in a pulp disintegrator. $50 \mathrm{~mL}$ was then transferred from this sample to a beaker for analysis. 


\section{Results and discussion}

Oxidation of cellulose in systems without a $\mathrm{pH}$ buffer

The $\mathrm{pH}$ of the suspension changes over time during oxidation. This is due to the formation of both hydroxide ions (from the decomposition of hydrogen peroxide) and organic acids, such as formic acid (during cellulose hydrolysis) (Jung et al. 2009; Wen

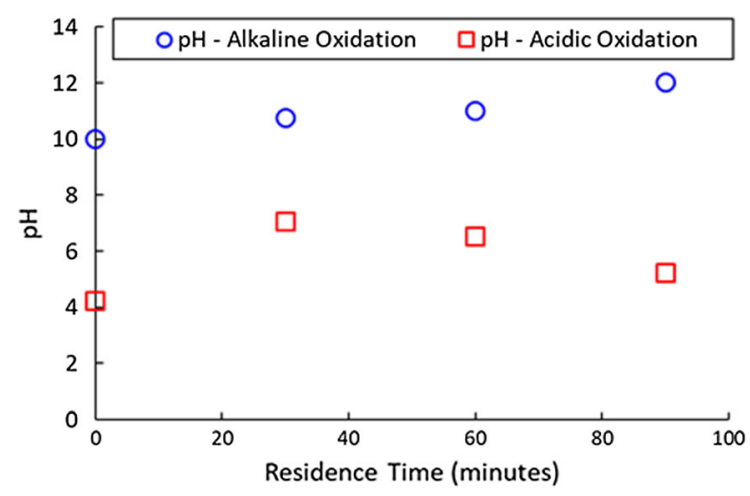

Fig. 2 Change in $\mathrm{pH}$ during oxidation in alkaline and acidic conditions et al. 2019). Figure 2 shows the change in $\mathrm{pH}$ during the oxidations performed under both acidic and alkaline conditions. The significant changes in $\mathrm{pH}$ that occur during the reaction mean that a suitable buffer is required to evaluate oxidation at a specific $\mathrm{pH}$.

Furthermore, a compositional analysis was carried out to investigate the extent to which the carbohydrates were affected during the reaction. The results reported in Table 1 show that the amount of hemicelluloses is slightly lower in the oxidized samples. The amount of non-detected material increases slightly, which is expected, due to the oxidation and hydrolysis of cellulose and hemicelluloses. This yields shorter, soluble fragments that cannot be detected by the method, such as humins (also known as pseudo-lignin) (van Zandvoort et al. 2013) or uronic acids. The mass of Klason lignin is also higher in the oxidized samples compared to the reference, something that has been reported previously for acid treatments of biomass (Sannigrahi and Ragauskas 2008). Li et al. (2005) reported that about $50 \%$ of Klason lignin may consist of humins.

The introduction of oxidized groups and the effect of oxidation on the chemical composition of the pulp was analysed in the samples presented in Table 1; the

Table 1 Results of the compositional analysis of the oxidized and reference sample

\begin{tabular}{|c|c|c|c|c|c|c|c|}
\hline & $\begin{array}{l}\text { Cellulose } \\
(\%)\end{array}$ & $\begin{array}{l}\text { Galacto-glucomannan } \\
(\%)\end{array}$ & $\begin{array}{l}\text { Xylan } \\
(\%)\end{array}$ & $\begin{array}{l}\text { ASL } \\
(\%)\end{array}$ & $\begin{array}{l}\text { Klason lignin } \\
(\%)\end{array}$ & $\begin{array}{l}\text { SUM } \\
(\%)\end{array}$ & $\begin{array}{l}\text { Not detected } \\
(\%)\end{array}$ \\
\hline $\begin{array}{l}\text { Bleached kraft } \\
\text { pulp }\end{array}$ & 70.7 & 7.44 & 8.23 & 0.77 & 0.00 & 87.2 & 12.8 \\
\hline $\begin{array}{l}\text { Acidic oxidation } \\
30 \mathrm{~min}\end{array}$ & 70.9 & 5.96 & 8.12 & 0.64 & 1.65 & 87.3 & 12.7 \\
\hline $\begin{array}{l}\text { Acidic oxidation } \\
60 \mathrm{~min}\end{array}$ & 70.9 & 5.16 & 7.95 & 0.70 & 1.40 & 86.2 & 13.8 \\
\hline $\begin{array}{l}\text { Acidic oxidation } \\
90 \mathrm{~min}\end{array}$ & 70.1 & 5.22 & 8.03 & 0.69 & 1.50 & 85.6 & 14.4 \\
\hline $\begin{array}{l}\text { Alkaline } \\
\text { oxidation } \\
30 \mathrm{~min}\end{array}$ & 69.9 & 6.43 & 8.49 & 0.66 & 1.70 & 87.2 & 12.8 \\
\hline $\begin{array}{l}\text { Alkaline } \\
\text { oxidation } \\
60 \mathrm{~min}\end{array}$ & 69.5 & 5.58 & 8.28 & 0.65 & 1.50 & 85.5 & 14.5 \\
\hline $\begin{array}{l}\text { Alkaline } \\
\text { oxidation } \\
90 \text { min }\end{array}$ & 69.6 & 5.97 & 8.25 & 0.67 & 1.40 & 85.9 & 14.1 \\
\hline
\end{tabular}



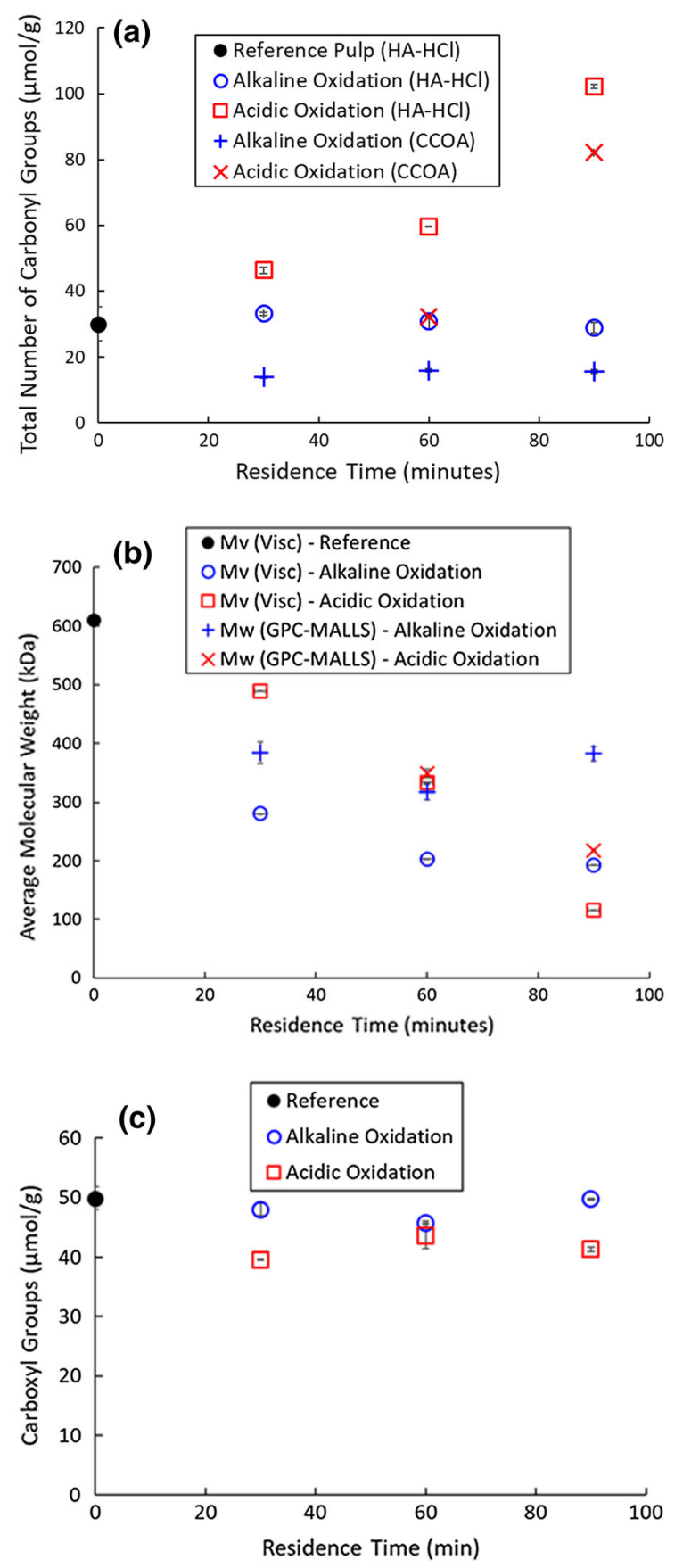

Fig. 3 a Total number of carbonyl groups in pulp oxidized using acidic and alkaline conditions, measured using the hydroxylamine hydrochloride method (HA-HCl) and CCOA labelling. Error bars calculated from the duplicates are included. b Average molecular weight, calculated from capillary viscosimetry and GPC measurements, of acidic and alkaline oxidations. Error bars calculated from the duplicates are included. c Carboxyl content of pulp oxidized at acidic and alkaline oxidations. Error bars calculated from the duplicates are included

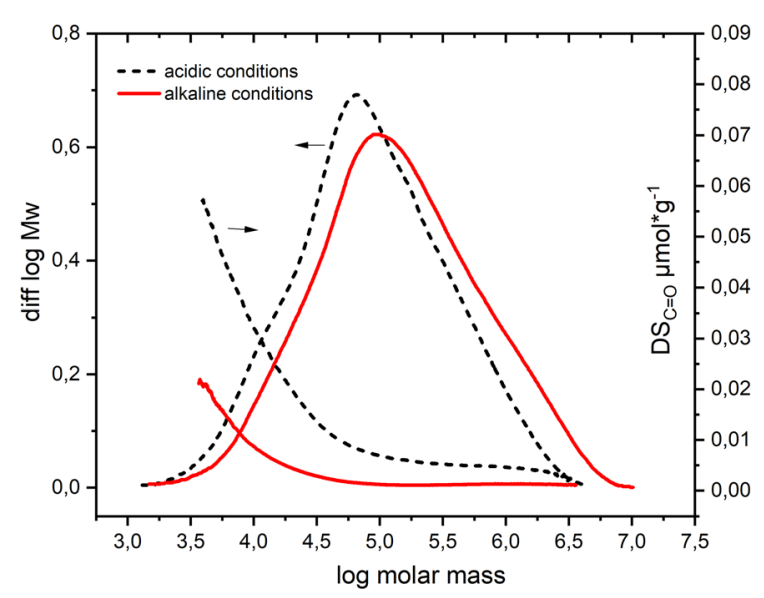

Fig. 4 Degree of oxidation (carbonyl content) and size distribution in samples oxidized for 90 min using acidic and alkaline conditions

results obtained from these analyses are to be found in Fig. 3a-c. The total carbonyl content was analysed using both the hydroxylamine hydrochloride method and CCOA labelling in combination with GPCMALLS. The degradation of the pulp was assessed using capillary viscosimetry as well as GPC, and the carboxyl groups were analysed using potentiometric titration. The standard deviation is low for the two carbonyl quantification methods however, the hydroxylamine hydrochloride method seems to overestimate the carbonyl content, compared to the results from GPC-MALLS. Although the two trends for total carbonyl content seem to correlate well, the DMAc$\mathrm{LiCl}$ system dissolves softwood pulps of larger molecular weight poorly and therefore no comparison could be made for two data points (reference and 30-min, acidic oxidation). The GPC results and the viscosity-average molecular weight results obtained from the capillary viscosimetry measurements also show similar trends. The carboxyl content of the oxidized pulp remained relatively unchanged throughout the oxidation, regardless of the $\mathrm{pH}$ of the oxidation.

Correlating the degree of oxidation with the molecular mass distributions and comparing those oxidized using acidic conditions with the alkaline ones (Fig. 4) shows a considerable increase in carbonyl groups throughout the size-range in the sample oxidized using acidic conditions, compared to that using alkaline conditions. However, the largest 
Table 2 Molecular weights and carbonyl content of the various oxidized pulps and the reference pulp

\begin{tabular}{llllccc}
\hline & $\mathrm{Mn}(\mathrm{kDa})$ & $\mathrm{Mw}(\mathrm{kDa})$ & $\mathrm{Mz}(\mathrm{kDa})$ & Dispersity $(\mathrm{Mw} / \mathrm{Mn})$ & $\mathrm{Reg}(\mu \mathrm{mol} / \mathrm{g})$ & $\mathrm{C}=\mathrm{O}(\mu \mathrm{mol} / \mathrm{g})$ \\
\hline Bleached kraft pulp & $(24.0)$ & $(311)$ & $(893)$ & $(12.8)$ & $(41.3)$ & $(6.90)$ \\
Acidic oxidation 30 min & $(28.0)$ & $(308)$ & $(886)$ & $(11.1)$ & $(36.5)$ & $(16.9)$ \\
Acidic oxidation 60 min & 43.2 & 349 & 1230 & 8.09 & 23.3 & 32.3 \\
Acidic oxidation 90 min & 33.6 & 218 & 858 & 6.48 & 29.8 & 82.1 \\
Alkaline oxidation 30 min & 41.8 & 384 & 1440 & 9.41 & 24.7 & 13.8 \\
Alkaline oxidation 60 min & 42.8 & 317 & 1250 & 7.40 & 23.4 & 19.9 \\
Alkaline oxidation 90 min & 52.4 & 382 & 1560 & 7.34 & 19.2 & 15.5 \\
\hline
\end{tabular}

Carbonyl groups are reported as total number of carbonyl groups $(\mathrm{C}=\mathrm{O})$ and theoretical number of reducing end groups (Reg), based on $\mathrm{Mn}$. The reference pulp and that oxidized for $30 \mathrm{~min}$ under acidic conditions are disregarded due to their poor solubility

Table 3 Total number of carbonyl groups measured using the hydroxylamine hydrochloride method, and viscosity-average molecular weight of three different buffered oxidations

\begin{tabular}{lll}
\hline Sample & $\begin{array}{l}\text { Carbonyl content } \\
(\mu \mathrm{mol} / \mathrm{g})\end{array}$ & $\mathrm{Mv}(\mathrm{kDa})$ \\
\hline Phosphate buffer, pH 5.8 & 66.4 & 240 \\
Acetate Buffer, pH 5.6 & 91.2 & 111 \\
Acetate Buffer, pH 4.0 & 115 & 91.5 \\
\hline
\end{tabular}

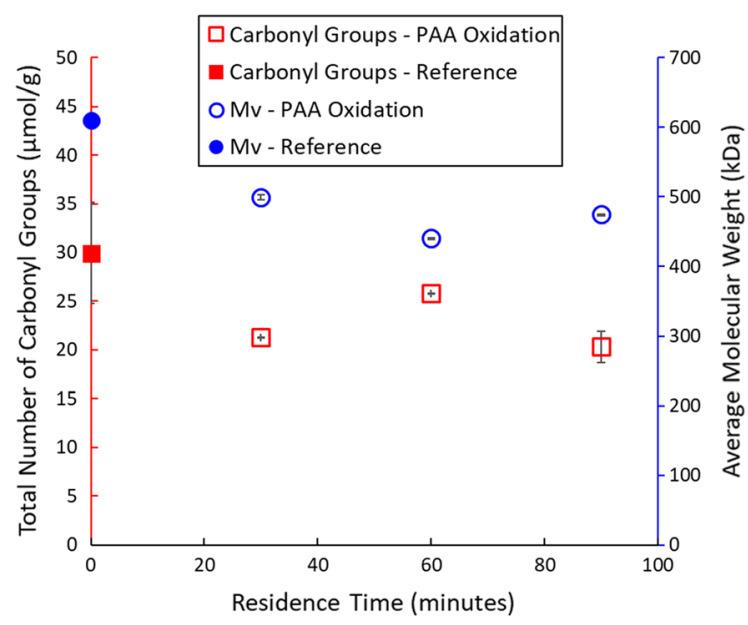

Fig. 5 Total number of carbonyl groups measured using the hydroxylamine hydrochloride method, and viscosity-average molecular weight of pulp oxidized using peracetic acid

increase can be found in the shorter chains, due to the formation of reducing ends.

The results of the GPC measurements for all of the experiments in this series are shown in Table 2. The maximum theoretical, amount of reducing end groups was estimated from $\mathrm{Mn}$ in order to estimate their maximal possible contribution to the total amount detected carbonyls. It can be seen that the theoretical number of reducing end groups remains fairly constant, whereas the total number of carbonyl groups increases quite rapidly during the course of the oxidations carried out in an acidic environment, which indicates the introduction of carbonyl groups along the chain (see also Fig. 4).

Oxidation of cellulose in systems with a pH-buffer

\section{Selection of buffer system}

The alkaline oxidation experiments did not lead to increased carbonyl contents, hence only acidic oxidations were studied further. In order to eliminate variations in the $\mathrm{pH}$ during oxidation, two different buffered systems were compared: a phosphate and an acetate buffer. These were evaluated at as close $\mathrm{pH}$ as possible but, as the $\mathrm{pH}$ ranges for these buffers do not overlap, a slight difference in $\mathrm{pH}$ had to be accepted. Two oxidations, performed in a $0.1 \mathrm{M}$ buffer solution with a residence time of $90 \mathrm{~min}$, were compared. The oxidation in the acetate buffer resulted in a larger number of carbonyl groups compared to that in the phosphate buffer, as can be seen in Table 3 . There may be several explanations for this: one is that phosphate acts as a stabilizer for hydrogen peroxide (Aggarwal et al. 1991; Kakarla and Watts 1997) and thereby leads to reduced oxidation power, and another may be the formation of peracetic acid, which is a strong oxidant, in the acetate-buffered system. The role of peracetic acid in oxidation therefore requires further evaluation. 

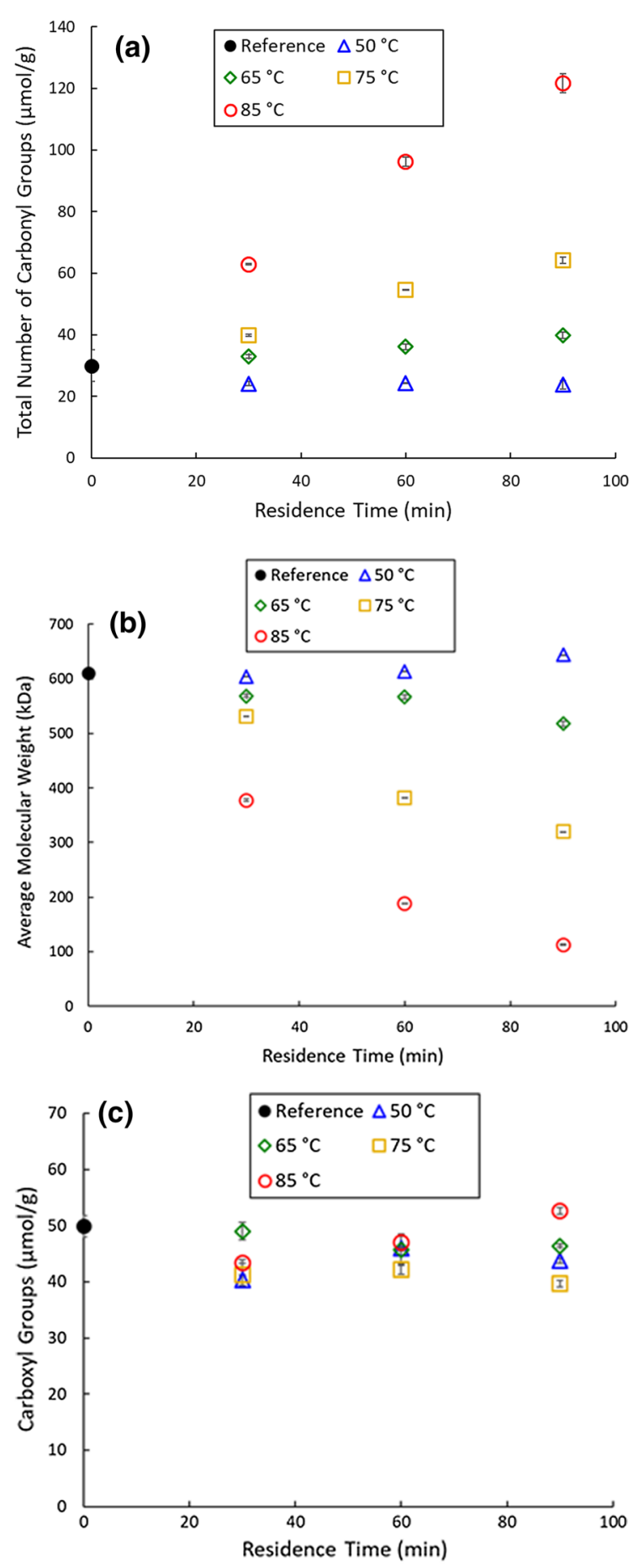

Reducing the $\mathrm{pH}$ to 4 in the acetate-buffered system further enhanced the introduction of carbonyl groups.

A series of oxidations using $5 \%$ peracetic acid in $0.1 \mathrm{M}$ acetate buffer ( $\mathrm{pH} 4.0$ ) were performed. No significant increase in carbonyl content was found
4Fig. 6 a Carbonyl content at four different oxidation temperatures, measured using the hydroxylamine hydrochloride method. Oxidations performed at $\mathrm{pH} 4$ in $0.1 \mathrm{M}$ acetate buffer. Error bars calculated from the duplicates are included. b Viscosity-average molecular weight at four different oxidation temperatures. Oxidations performed at $\mathrm{pH} 4$ in $0.1 \mathrm{M}$ acetate buffer. Error bars calculated from the duplicates are included. c Carboxyl content at four different oxidation temperatures. Oxidations performed at $\mathrm{pH} 4$ in $0.1 \mathrm{M}$ acetate buffer. Error bars calculated from the duplicates are included

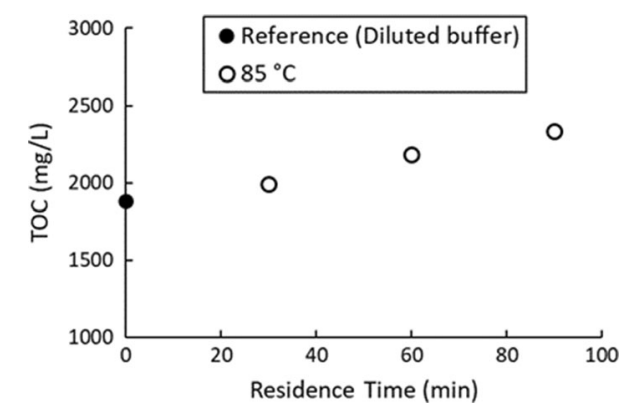

Fig. 7 TOC of the reaction solution subjected to acidic oxidation at $85{ }^{\circ} \mathrm{C}$. Reaction performed at $\mathrm{pH} 4$ in $0.1 \mathrm{M}$ acetate buffer

(however, a slight decrease can be noted) and only a slight decrease in viscosity-average molecular weight was observed, see Fig. 5. Consequently, the peracetic acid does not contribute significantly to the formation of carbonyl groups at the conditions investigated in this study.

Acetate was the buffer of choice for further investigations not only because peracetic acid did not seem to contribute to any carbonyl formation but also due to the fact that phosphate may have an undesired stabilizing effect on the oxidant.

\section{Influence of reaction temperature}

Four different reaction temperatures between 50 and $85{ }^{\circ} \mathrm{C}$ were investigated to evaluate the influence of reaction temperature when the carbonyl content, carboxyl content and viscosity-average molecular weight were determined (Fig. 6a-c). As expected, the reaction rate increases with increased reaction temperature: this can be seen from the increase in the formation of carbonyl group as well as the increase in degradation of the cellulose. However, previous results of GPC-MALLS analysis show that the total carbonyl content increases faster than the theoretical number of reducing end groups. At residence times shorter than 
Fig. 8 The reference (top left) and oxidized (top right) sheets of pulp 10 min after submersion in water. The same reference (bottom left) and oxidized (bottom right) sheets after magnetic stirring
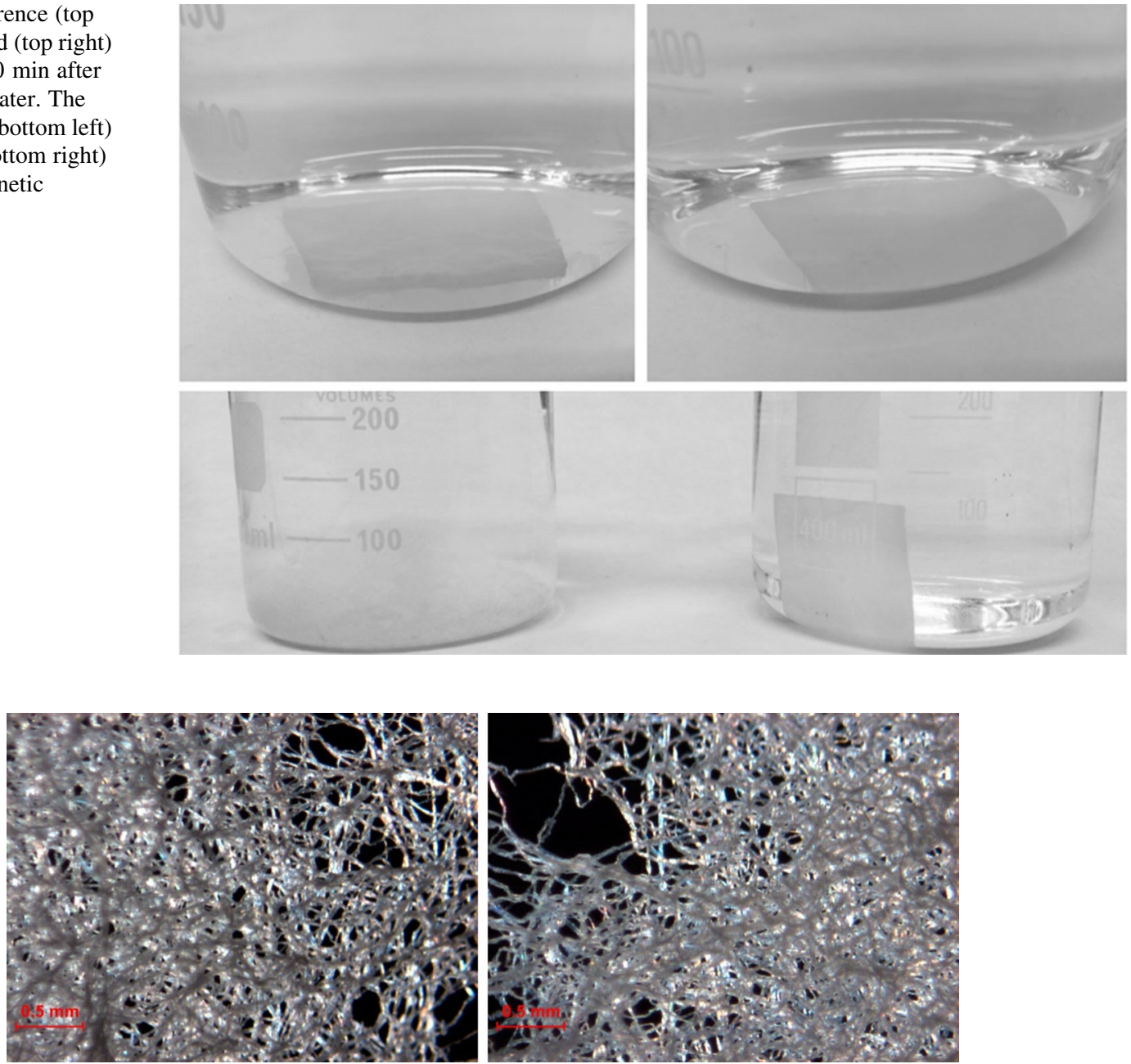

Fig. 9 Light microscopy images of the fibre networks in the reference (left) and oxidised (right) pulp

$60 \mathrm{~min}$, acidic conditions were found to result in a lower decrease in molecular weight than alkaline conditions. When comparing oxidation for $60 \mathrm{~min}$ at $85^{\circ} \mathrm{C}$, the buffered reaction at $\mathrm{pH} 4$ and the alkaline, unbuffered, oxidation resulted in similar viscosityaverage molecular weights (189 and $204 \mathrm{kDa}$ ). However, the acidic oxidation resulted in a threefold increase in carbonyl groups compared to the reference and the pulp oxidized at alkaline conditions.

It is interesting to note that, despite the obvious variations in the number of carbonyl groups introduced, the number of carboxyl groups in the pulp seems to be more or less constant. Highly oxidized fractions are generally more soluble in aqueous solutions because of the increased number of carboxyl groups and chain cleavage, which is extensive in these fractions. This may cause a portion of the fractions containing carboxyl groups to dissolve and, subsequently, be washed out of the sample. This hypothesis was supported by the results of the total organic carbon (TOC) measurements of the liquors obtained after oxidation. The liquors show an increase in TOC content with increasing residence times, see Fig. 7.

\section{Wet durability}

Carbonyl groups can affect the properties of the pulp material in multiple ways, for example by decreasing brightness stability and leading to discoloring of the final products, which has been studied in recent works (Ahn et al. 2019). It is known that polysaccharides with carbonyl functionalities can cross-link through 
Reference Pulp

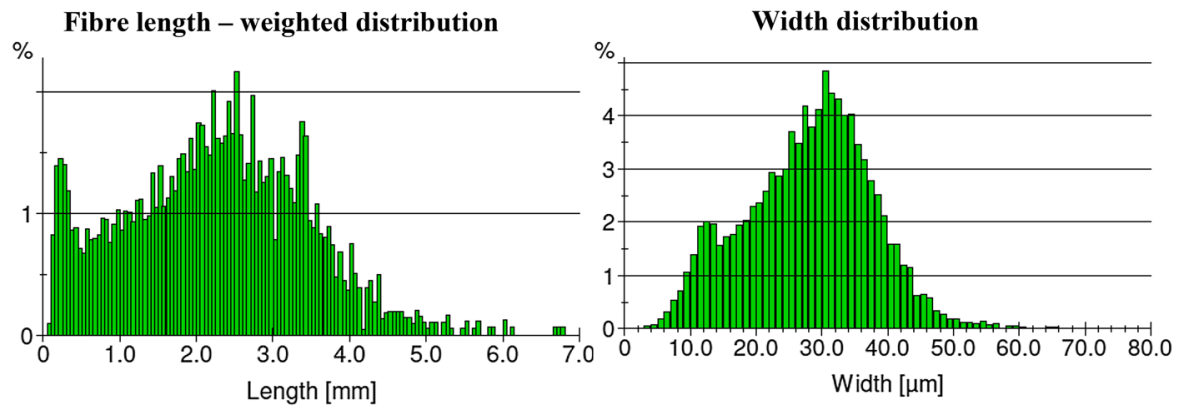

Oxidized Pulp

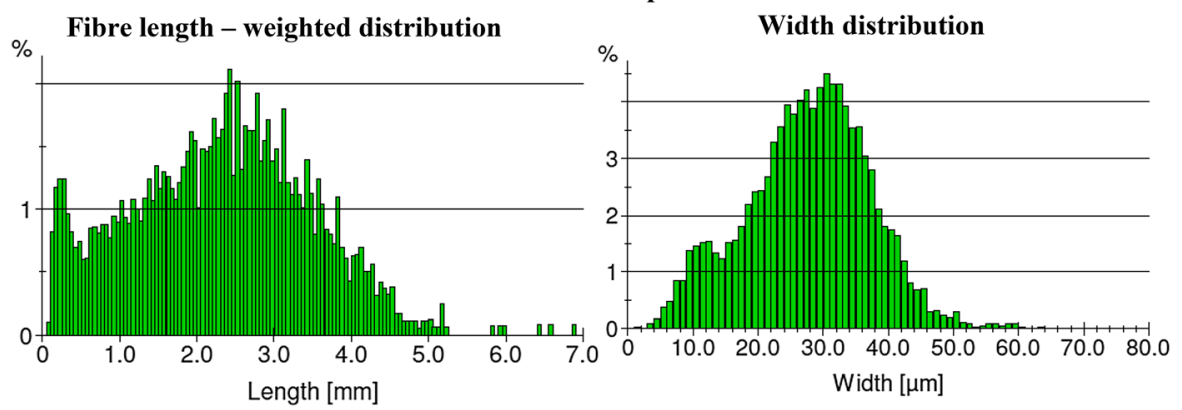

Fig. 10 Length weighted length distribution and width distribution of the reference (above) and oxidized (below) pulp

Table 4 Length weighted fibre length and arithmetic fibre width of the reference and oxidized pulp

\begin{tabular}{lcc}
\hline & Reference pulp & Oxidized pulp \\
\hline $\mathrm{L}(\mathrm{l})(\mathrm{mm})$ & 2.20 & 2.26 \\
$\mathrm{~W}(\mathrm{n})(\mu \mathrm{m})$ & 26.1 & 25.8 \\
\hline
\end{tabular}

the formation of hemiacetal bonds and that it contributes to the wet strength of paper (Saito and Isogai 2005). A simple experiment was performed to investigate whether or not fibre networks formed by the oxidised pulp used in this study are more stable in water than those formed by an unmodified pulp. Two sheets were prepared: one from an unmodified pulp (reference) and one from a highly oxidized pulp that was oxidized at acidic conditions (carbonyl content: $121.6 \mu \mathrm{mol} / \mathrm{g}$ ). The two sheets were placed in separate beakers containing $300 \mathrm{ml}$ of water. After $10 \mathrm{~min}$ of exposure to the water, the reference sample was noticeably more swollen than the oxidized sample, which maintained a compact structure, see Fig. 8. No noticeable change could be observed during the following $2 \mathrm{~h}$. After $48 \mathrm{~h}$, the surface of the reference pulp began to disintegrate and loose fibres were observed. Furthermore, $1 \mathrm{~min}$ of stirring with a magnetic stir bar at $120 \mathrm{rpm}$ resulted in the complete disintegration of the reference sample whereas the oxidized sample maintained its structure. This simple experiment shows the structure of the paper prepared from the oxidized pulp to be remarkably stable in wet conditions, the most likely explanation for which is the formation of hemiacetal bonds. Furthermore, the very limited swelling of the sheet makes it reasonable to assume that inter-fibre hemiacetal bonds are formed. The experiment was repeated with a pulp subjected to conditions identical to those of the oxidized pulp $\left(85^{\circ} \mathrm{C}, \mathrm{pH} 4\right.$ acetate buffer, 90 min reaction time), but without the presence of hydrogen peroxide, to determine whether the beating effect of the stirring or the presence of the buffer could have affected the resistance to water. The sheet produced from this pulp showed an identical behaviour to the reference pulp: noticeable swelling occurred and the sheet disintegrated rapidly under stirring with a stir bar. This further strengthens the theory that hemiacetal bonds are responsible for the increased resistance to disintegration in water. 
Potential visual differences between the fibre networks prepared by the oxidised pulp $(90 \mathrm{~min}, \mathrm{pH}$ 4) and a reference pulp (fully bleached kraft pulp) were investigated by preparing two thin fibre networks and analysing them using light microscopy. The resulting images (Fig. 9) show that no significant difference can be found between the two samples. The fibre dimensions seem virtually unaffected by the oxidising treatment and the resulting networks are visually similar. This indicates that the resulting changes in properties, such as reduced swelling and increased resistance to disintegration in water, are more likely due to chemical modification rather than physical changes in the fibre morphology itself, such as the beating effects of the stirring during the reaction. This was supported by further analysis carried out using a Kajaani FS300 fibre image analyser. An oxidized pulp ( $90 \mathrm{~min}, 85^{\circ} \mathrm{C}, \mathrm{pH} 4$ ) was compared to the unoxidized reference pulp; the length weighted fibre length and width distribution can be found in Fig. 10 and the resulting average lengths and widths in Table 4. The results are within the margin of error for the analysis and indicate similar fibre dimensions. This potentially indicates that oxidation, and subsequent cross-linking, predominantly occur on the fibre surface: the swelling of the fibre is not inhibited in the oxidized sample, which could be the case if cross-linking occurred extensively within the fibre wall.

\section{Conclusions}

In this study it has been shown that acidic oxidation, using hydrogen peroxide at reaction temperatures between 75 and $85{ }^{\circ} \mathrm{C}$, increased the formation of carbonyl groups significantly when compared to oxidation at alkaline conditions. When formed into a network, the material proved to have a low degree of swelling and a structural integrity at aqueous conditions, even after $48 \mathrm{~h}$ had passed. The low degree of swelling of the material and the ability to maintain the fibre network when submerged in water indicate the formation of inter-fibrillar covalent bonds, most likely hemiacetals. On the other hand, the decrease in degree of polymerization most likely implies that the strength of the fibres most likely will decrease. The conditions investigated in this study can be easily applied in a typical industrial bleaching stage.
Acknowledgments Open access funding provided by Chalmers University of Technology. This work has been carried out as a part of the AvanCell network, which is a research collaboration between Södra Innovation and Chalmers University of Technology. Financial support from the Södra Foundation for Research, Development and Education is gratefully acknowledged.

\section{Compliance with ethical standards}

Conflict of interest The authors declare that they have no conflict of interest.

Open Access This article is licensed under a Creative Commons Attribution 4.0 International License, which permits use, sharing, adaptation, distribution and reproduction in any medium or format, as long as you give appropriate credit to the original author(s) and the source, provide a link to the Creative Commons licence, and indicate if changes were made. The images or other third party material in this article are included in the article's Creative Commons licence, unless indicated otherwise in a credit line to the material. If material is not included in the article's Creative Commons licence and your intended use is not permitted by statutory regulation or exceeds the permitted use, you will need to obtain permission directly from the copyright holder. To view a copy of this licence, visit http://creativecommons.org/licenses/by/4.0/.

\section{References}

Aggarwal P, Means JL, Downey DC (1991) Use of hydrogen peroxide as an oxygen source for in situ biodegradationpart II. Laboratory studies. J Hazard Mater 27:301-314. https://doi.org/10.1016/0304-3894(91)80056-T

Ahn K, Zaccaron S, Zwirchmayr NS, Hettegger H, Hofinger A, Bacher M, Henniges U, Hosoya T, Potthast A, Rosenau T (2019) Yellowing and brightness reversion of celluloses: $\mathrm{CO}$ or $\mathrm{COOH}$, who is the culprit? Cellulose 26:429-444. https://doi.org/10.1007/s10570-018-2200-x

Barbosa LC, Maltha CR, Demuner AJ, Cazal CM, Reis EL, Colodette JL (2013) A rapid method for quantification of carboxyl groups in cellulose pulp. BioResources 8(1):1043-1054. https://doi.org/10.15376/biores.8.1.10431054

Bates R, Beijer P, Podd B (1999) Wet strengthening of paper. In: Neimo L (ed) Papermaking chemistry. Fapet Oy, Helsinki, pp 289-302

Dunlop-Jones N (1991) Wet-strength chemistry. In: Roberts JC (ed) Paper chemistry. Chapman and Hall, New York, pp 76-96

Epsy HE, Geist GW (1993) Persulfates as repulping reagents for neutral/alkaline wet-strength broke. Tappi J 76(2):139-142

Gierer J (1997) Formation and involvement of superoxide $\left(\mathrm{O}_{2}-/\right.$ $\left.\mathrm{HO}_{2}^{-}\right)$and Hydroxyl $\left(\mathrm{OH}^{-}\right)$radicals in TCF bleaching processes: a review. Holzforschung 51:34-46. https://doi.org/ 10.1515/hfsg.1997.51.1.34

Gullichsen J, Fogelholm CJ (1999) Chemical pulp. Fapet Oy, Helsinki 
Hosoya T, Bacher M, Potthast A, Elder T, Rosenau T (2018) Insights into degradation pathways of oxidized $\beta$-alkoxyelimination: a combined theoretical and experimental approach. Cellulose 25:3797-3814. https://doi.org/10. 1007/s10570-018-1835-y

Jedvert K, Wang Y, Saltberg A, Henriksson G, Lindström ME, Theliander H (2012) Mild steam explosion: a way to activate wood for enzymatic treatment, chemical pulping and biorefinery processes. Biorefinery 27(5):828-835. https:// doi.org/10.3183/npprj-2012-27-05-p828-835

Jung YS, Lim WT, Park J-Y, Kim Y-H (2009) Effect of pH on Fenton and Fenton-like oxidation. Environ Technol 30(2):189-190. https://doi.org/10.1080/ 09593330802468848

Kakarla PK, Watts RJ (1997) Depth of Fenton-like oxidation in remediation of surface soil. J Environ Eng 123(1):11-17. https://doi.org/10.1061/(ASCE)0733-9372(1997)123: $1(11)$

Kes M, Christensen BE (2013) A re-investigation of the MarkHouwink-Sakurada parameters for cellulose in cues: a study on size-exclusion chromatography combined with multi-angle light scattering and viscometry. J Chromatogr 1281:32-37. https://doi.org/10.1016/j.chroma.2013.01. 038

Lewin M (1997) Oxidation and aging of cellulose. Macromol Symp 118:715-724. https://doi.org/10.1002/masy. 19971180192

Li J, Henriksson G, Gellerstedt G (2005) Carbohydrate reactions during high-temperature steam treatment of aspen wood. Appl Biochem Biotech 125(3):175-186. https://doi.org/10. 1385/abab:125:3:175

Meier H (1958) Studies on hemicelluloses from pine (Pinus silvestris L.). Acta Chem Scand 12:1911-1918. https://doi. org/10.3891/acta.chem.scand.12-1911

Münster L, Vícha J, Klofáč J, Masař M, Kucharczyk P, Kuřitka I (2017) Stability and aging of solubilized dialdehyde cellulose. Cellulose 24:2753-2766. https://doi.org/10.1007/ s10570-017-1314-x
Röhrling J, Potthast A, Rosenau T, Lange T, Borgards A, Sixta $\mathrm{H}$, Kosma P (2002) A novel method for the determination of carbonyl groups in cellulosics by fluorescence labeling. 2 Validation and applications. Biomacromol 3(5):969-975. https://doi.org/10.1021/bm020030p

Rutherford HA, Harris M (1943) Oxycellulose. In: Ott E (ed) Cellulose and cellulose derivatives part 1. Interscience Publishers, New York, pp 175-192

Saito T, Isogai A (2005) A novel method to improve wet strength of paper. Tappi J 4(3):3-8

Sannigrahi P, Ragauskas AJ (2008) Effects of two-stage dilute acid pretreatment on the structure and composition of lignin and cellulose in loblolly pine. Bioenerg Res 1:205-214. https://doi.org/10.1007/s12155-008-9021-y

Theander O, Westerlund E (1986) Studies on dietary fiber. 3. Improved procedures for analysis of dietary fiber. J Agric Food Chem 34(2):330-336. https://doi.org/10.1021/ jf00068a045

van Zandvoort I, Wang Y, Rasrendra CB, van Eck ER, Bruijnincx PC, Heeres HJ, Weckhuysen BM (2013) Formation, molecular structure, and morphology of humins in biomass conversion: influence of feedstock and processing conditions. Chemsuschem 6(9):1745-1758. https://doi.org/10. 1002/cssc. 201300332

Wen J, Yin Y, Peng X, Zhang S (2019) Using $\mathrm{H}_{2} \mathrm{O}_{2}$ to selectively oxidize recyclable cellulose yarn with high carboxyl content. Cellulose 26:2699-2713. https://doi.org/10.1007/ s10570-018-2217-1

Zhao H, Heindel ND (1990) Determination of degree of substitution of formyl groups in polyaldehyde dextran by the hydroxylamine hydrochloride method. Pharm Res 8(3):400-402. https://doi.org/10.1023/A:1015866104055

Publisher's Note Springer Nature remains neutral with regard to jurisdictional claims in published maps and institutional affiliations. 